2. Steyers CM III, Khera R, Bhave P. Pacemaker dependency after cardiac surgery: a systematic review of current evidence. PLoS One. 2015;10: e0140340.
3. Auffret V, Puri R, Urena M, Chamandi C, Rodriguez-Gabella T, Philippon F, et al Conduction disturbances after transcatheter aortic valve replacement. Current status and future perspectives. Circulation. 2017;136:1049-69.
See Article page 816.

\section{Commentary: Timing is everything: Permanent pacemaker implantation following cardiac surgery}

\author{
Magdy M. El-Sayed Ahmed, MD, MS, a,b and \\ Kevin P. Landolfo, MD, MS
}

Conduction disturbances occur commonly following cardiac surgical procedures. Although most bradyarrhythmias recover spontaneously, permanent pacemaker (PPM) implantation rates are reported from $0.8 \%$ to $4 \%$ after cardiac surgery. ${ }^{1}$ Furthermore, despite the advances of transcatheter approaches for treatment of aortic valvular heart disease, PPM rates continue to exceed $10 \%$ and remain a barrier to broad acceptance of the procedure in low-risk populations. Although early PPM implantation has been advocated to shorten intensive care unit stay and improve postoperative recovery, morbidity from indwelling pacemakers occurs. ${ }^{2}$ In addition, only one half of patients receiving early PPM implantation are pacemaker dependent at follow-up. ${ }^{3}$ Consensus American College of Cardiology/ American Heart Association guidelines regarding postoperative PPM implantation lack specificity regarding indications and timing. ${ }^{4,5}$

In the current issue of the Journal, Bis and colleagues ${ }^{6}$ report a single-institution retrospective analysis of PPM implantation following cardiac surgery over a 10-year period (2008-2019) in 15,092 patients. PPM implantation

\footnotetext{
From the ${ }^{\mathrm{a} D e p a r t m e n t}$ of Cardiothoracic Surgery, Mayo Clinic, Jacksonville, Fla; and ${ }^{\mathrm{b}}$ Department of Surgery, Zagazig University Faculty of Human Medicine, Zagazig, Egypt.

Disclosures: Authors have nothing to disclose with regard to commercial support.

Received for publication Feb 12, 2020; accepted for publication Feb 15, 2020; available ahead of print Feb 21, 2020.

Address for reprints: Kevin P. Landolfo, MD, MS, Department of Cardiothoracic Surgery, Mayo Clinic, 4500 San Pablo Rd S, Jacksonville, FL 32224 (E-mail: landolfo. kevin@mayo.edu).

J Thorac Cardiovasc Surg 2021;162:827-8

$0022-5223 / \$ 36.00$

Copyright (C) 2020 by The American Association for Thoracic Surgery

https://doi.org/10.1016/j.jtcvs.2020.02.063
}

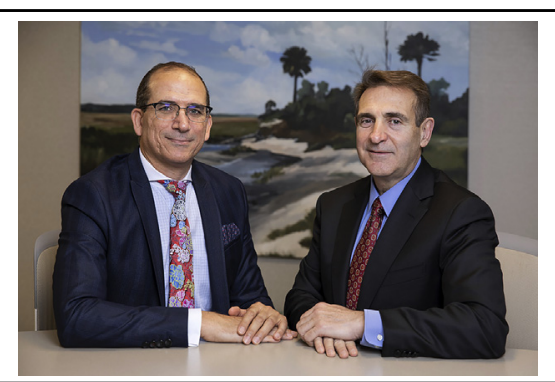

Magdy M. El-Sayed Ahmed, MD, MS (left), and Kevin P. Landolfo, MD, MS (right)

\author{
CENTRAL MESSAGE \\ Timing of postoperative perma- \\ nent pacemaker implantation is \\ important to minimize morbidity \\ and avoid prolonged \\ hospitalization.
}

was performed postoperatively in 177 patients $(1.2 \%)$. The study population consisted of a heterogeneous group of cardiac surgical patients with the indications and timing of PPM implantation left to the discretion of the surgeon and consulting electrophysiologist. PPM implantation was most commonly performed following isolated valve replacement (aortic valve replacement $>$ mitral valve replacement), with atrioventricular (AV) block as the underlying rhythm in $73 \%$. Most importantly, at intermediate follow-up (median 2.75 years), one half of the patients were not pacemaker dependent and $45 \%$ had complete recovery of AV conduction. Multivariable analysis showed that the need for pacing was predicted by number of days between surgery and PPM insertion. Specifically, the shorter number of days between surgery and PPM implantation, the less likely the patient was to be pacer-dependent at follow-up. Receiver operating curve analysis demonstrated that PPM implantation with a cutoff at day 6 was more likely to be pacer independent at follow-up. In addition, sinus node dysfunction as the indication for PPM increased 6-fold the probability of no pacing dependence at follow-up. 
The authors describe an important clinical scenario following cardiac procedures with regards to PPM implantation. They suggest that early implantation of a PPM may lead to increased morbidity in patients who recover normal AV conduction and ultimately have no clinical indication for a pacemaker. Given their assertions and lack of specific American College of Cardiology/American Heart Association guidelines, how should the results of this study be incorporated into surgical practice? The suggestion to delay PPM implantation until a week postoperatively in all patients would result in increased length of hospital stay and create potential morbidity in many patients. Therefore, it seems appropriate to delay (postoperative day 7) PPM implantation in all patients with sinus-node dysfunction following nonvalvular procedures as suggested. Patients undergoing valvular procedures with high-grade persistent $\mathrm{AV}$ conduction block remain problematic. PPM implant timing at 7 days remains controversial. However, given the well-described long-term morbidity following PPM insertion, close follow-up to determine the continued need for pacing in all patients is essential. Consideration and removal of unnecessary pacemakers may be warranted. "Timing may indeed be everything," but further study is required to optimize the algorithm for pacemaker implantation following cardiac procedures.

\section{References}

1. Chung MK. Cardiac surgery: postoperative arrhythmias. Crit Care Med. 2000;28: N136-44.

2. Greason KL, Lahr BD, Stulak JM, Cha YM, Rea RF, Schaff HV, et al. Long-term mortality effect of early pacemaker implantation after surgical aortic valve replacement. Ann Thorac Surg. 2017;104:1259-64.

3. Goldman BS, Williams WG, Hill T, Hesslein PS, McLaughlin PR, Trusler GA, et al. Permanent cardiac pacing after open heart surgery: congenital heart disease. Pacing Clin Electrophysiol. 1985:8:732-9.

4. Glikson M, Dearani JA, Hyberger LK, Schaff HV, Hammill SC, Hayes DL, et al. Indications, effectiveness, and long-term dependency in permanent pacing after cardiac surgery. Am J Cardiol. 1997;80:1309-13.

5. Epstein AE, DiMarco JP, Ellenbogen KA, Estes NA III, Freedman RA, Gettes LS, et al. ACC/AHA/HRS 2008 guidelines for device-based therapy of cardiac rhythm abnormalities: a report of the American College of Cardiology/American Heart Association Task Force on Practice Guidelines (Writing Committee to Revise the ACC/AHA/NASPE 2002 Guideline Update for Implantation of Cardiac Pacemakers and Antiarrhythmia Devices) developed in collaboration with the American Association for Thoracic Surgery and Society of Thoracic Surgeons. J Am Coll Cardiol. 2008:51:e1-62.

6. Bis J, Gościńska-Bis K, Gołba KS, Gocoł R, Zębalski M, Deja MA. Permanent pacemaker implantation after cardiac surgery: optimization of the decision process. J Thorac Cardiovasc Surg. 2021;162:816-24.e3. 